\title{
Opportunities for lignin valorization: an exploratory process
}

\author{
Stephen P. Cline ${ }^{*}$ (i) and Paul M. Smith
}

\begin{abstract}
Background: For decades, the pulp industry has struggled to create sustainable value-added opportunities for lignin, and the issue is now at the forefront of second-generation biorefinery research and development efforts. Our work presents a sequential process for examining potential lignin valorization. The chemical and physical properties of lignin cause issues in isolation, characterization, and standardization and, therefore, product manufacturing. First, a short list of high-opportunity lignin products was developed from the literature. Several low-hanging product opportunities were identified, from which, lignin-based powdered activated carbon (PAC) for the sequestration of mercury from power plant flue gas was selected for further examination due, in part, to lignin's similarity to lignite coal. Next, an analysis of the web-based written content of PAC suppliers' promotional materials was performed to assess the attributes on which PAC products are sold and purchased. Finally, potential electric generating power plant buyers/users of lignin-based PAC for mercury sequestration were surveyed to examine the importance of 16 PAC product and service attributes, identify potential entry barriers for a new PAC product, and assess the market opportunity for lignin-based PAC.
\end{abstract}

Methods: This research deployed a multi-phase market analysis based process including: a PAC vendor content analysis; and survey techniques. Phase I analyzed web-based content of PAC vendors' promotional marketing literature tailored to power plant buyers/users for their PAC products. Phase II incorporated the Phase I results into an exploratory e-survey of select PAC buyers/users in the U.S. power generation industry. Combining these methods provides an exploratory market perspective on lignin valorization.

Results: The top three product and service attributes for buyers/users of PAC for mercury mitigation were Product Reliability, Product Effectiveness, and Proven Product Performance; the top three barriers to entry for a new ligninbased PAC include Title V Permitting, Operational Impacts, and Compliance with Regulations. Buyers/users are undecided about trial testing a lignin-based PAC product.

Conclusions: This paper provides a logical and systematic process for exploring new product opportunities in business-to-business markets and provides insights into the market potential for lignin-based PAC for mitigating mercury emissions from US electric generating power plants.

Keywords: Lignin, Lignin valorization, New product development, Activated carbon, Mercury and air toxic standards (MATS), Mercury sequestration, Electric generating power plants, Biorefinery

\footnotetext{
* Correspondence: cline.stephen@gmail.com

The Pennsylvania State University, University Park, Pennsylvania, United States
} 


\section{Background}

The corn-grain ethanol industry accounts for nearly $10 \%$ of gasoline consumption in the US transportation sector [1]. However, public pressure on food vs. fuel and the $10 \%$ maximum ethanol blend wall are moving biofuel investment toward next generation lignocellulosic biofuels [2]. These second generation biofuels first separate the carbohydrate fraction (cellulose and hemicellulose) from lignin waste and then convert the fermented sugars into fuels [2-5]. Lignin constitutes 15 to $40 \%$ dry weight of lignocellulosic feedstock resulting in a large waste stream [4]. Lignin, an established byproduct of pulp mills, has traditionally been burned for combined heat and power. However, in second generation biorefineries, approximately $60 \%$ more lignin is generated than what is needed to meet plant energy needs through combustion $[6,7]$. As a result, research efforts are accelerating to identify viable opportunities for lignin valorization.

In 1927, Marathon Corporation began efforts to commercialize lignosulphonate products, but outlets did not begin coming to fruition until 1948 [8, 9]. The pulp industry, currently the world's largest producer of lignin, has benefited little from value-added lignin products despite advances in lignin valorization research [4]. Conversion of lignin into commercial chemicals, materials, and fuels is costly due to physical and chemical properties, including its heterogeneous structure, impurity from isolation, and unique reactivity $[4,6,10-14]$.

A dearth of literature exists addressing ways to bring value-added lignin products to market. This study introduces a multi-phase, systematic process to evaluate market opportunities for lignin valorization beginning with a thorough review of literature. From the literature, various current applications emerged including vanillin, cement dispersion, and low-grade fuel. Potential ligninbased applications include aromatics, agrochemicals, polymers, and high-performance materials [12]. Ligninbased powdered activated carbon for mercury sequestration was identified as a "low-hanging" value-added opportunity. Mercury is mitigated by injecting PAC into the flue gas through an activated carbon injection (ACI) system, where the PAC adsorbs the mercury into its structure. The high potential for PAC is due, in part, to current US policies leading to market growth opportunities and the porosity of lignin-based PAC. The full rationale for PAC will be discussed in subsequent sections of this paper, but in essence, the lignin valorization process then proceeded with PAC as the product identified for subsequent analysis (Table 1). Phase I included a vendor content analysis of promotional materials used by vendors to market their PAC for mercury mitigation from power plant flue gas (Table 1). Finally, Phase II included this vendor content in surveys of PAC buyers/ users to identify salient product and service purchase
Table 1 Multi-phase process for new lignin product-market opportunity research

\begin{tabular}{ll}
\hline Problem: & \\
Value-added applications for biorefinery & waste lignin \\
Phase I: & Phase Il: \\
PAC vendor content analysis & PAC buyer/user survey \\
Objective: & Objective: \\
Assess the criteria in which PAC is & Explore attributes in which \\
currently promoted by vendors & lignin-based PAC for mercury \\
& sequestration from electric \\
& generation power plant flue \\
& gas is purchased, examine \\
& barriers to entry and market \\
Implications: & opportunity \\
- The process may be applied to investigate other value-added \\
opportunities.
\end{tabular}

criteria (attributes) and potential barriers to entry for a new PAC product (Table 1).

\section{Lignin valorization}

Lignin was discovered in 1838 by Anselme Payen when wood reacted in an acidic then alkaline solution, resulted in an insoluble residue [15]. Since then, over 10,000 scientific papers have been published on lignin, each contributing to a puzzle that remains incomplete today [16].

In the plant, lignin has major processes necessary for plant life, by providing structure, energy storage, mechanical and biochemical stress protection, antioxidant protection, and water transportation [17]. Lignin's basic chemical structure is comprised of three separate molecules: conifery alcohol, sinapyl alcohol, and p-courmaryl alcohol (Chen, 2005). The molecules tend to bond to one another in random formations within lignin, making the molecule heterogeneous in nature, difficult to isolate, characterize, and standardize, which affects researchers' ability to formulate lignin into chemically reproducible products. Leading researchers have sought applications where the heterogeneous structure has had little effect on the reproducibility and consistency of a lignin-based product (I. Dallmeyer, personal communication, October 15, 2015; [17-20]).

Globally, approximately 50 million tons of lignin is produced annually, while lignin-derived products represent 1 to $2 \%$ of the world's lignin production and the remaining $98 \%$ is burned for energy or landfilled [14, 21-24]. Energy captures the most market volume, although it offers the lowest value-added opportunity [25]. Current lignin products can be segmented into several categories: binding agents, rheology control, dispersing agents, emulsion stabilizers, and retardants [21, 24] (Fig. 1). Concrete additives are a value-added application for lignin waste 


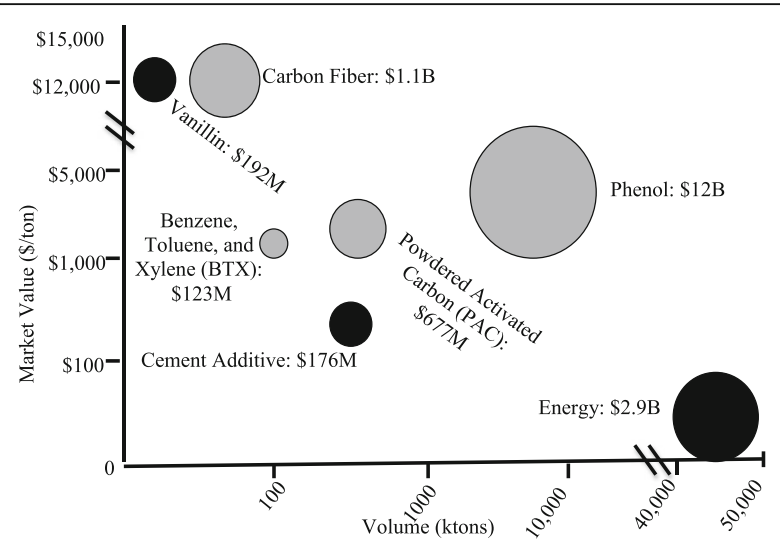

Fig. 1 Depiction of lignin products based on volume and value from literature $[2,29,64,77,78]$. The diameter of the circle represents the total market value of the product. Gray circles represent potential markets for lignin products, while black circles represent lignin products currently on the market

to reduce water usage in concrete and retard concrete setting time [21, 24]. Vanillin is a unique value-added product from lignin that is exclusively manufactured by Borregaard as a flavoring agent [26]. The lignin product market has grown from $\$ 2$ million in 1960 to $\$ 180$ million in 1984 [27] to $\$ 730$ million in 2014 [28], excluding energy.

Markets for potential lignin-based products vary in terms of volume and value, creating different strategic opportunities for biorefineries to add value to lignin (Fig. 1). Whereas lignin-based phenol and carbon fiber are poised to capture the largest market potential, factors such as cost of production and viable chemical pathways to products limit commercial feasibility $[4,29]$.

An alternative potential market with lower volume and value potential is lignin-based benzene, toluene and xylene (BTX), which requires a depolymerization of lignin followed by separation, of which there are technology limitations [12,30]. As shown, lignin's valorization can be separated into several greater categories of value-added applications, feedstock for energy production, a raw material in low-volume, high-value chemicals, a raw material in high volume, low value chemicals, and as a "precursor for material applications" [31]. Powdered activated carbon (PAC) is another potential market due to lignin's high carbon content, abundant supply, and the changing regulatory landscape for electric generating power plants [17, 32-34].

PAC for removing mercury from power plant flue gas streams is traditionally manufactured from lignite coal due to the coal's ability to generate proper PAC structure. Lignin is a precursor to lignite coal through a three-step geochemical process that transforms lignin into lignite coal. This process is known as coalification, which includes microbiological degradation of cellulose, the conversion of lignin into humic substances, and the condensation of the humic substances into coal molecules [35]. The lignin molecule is estimated to experience a dehydroxylation process, a cleavage of the B-O-4 ether bond, and a demethylation process to coalify lignin into lignite coal [36]. Due to the similarities between lignin and lignite coal, lignin has potential as a feedstock for the production of powdered activated carbon for mercury sequestration (Fig. 2).

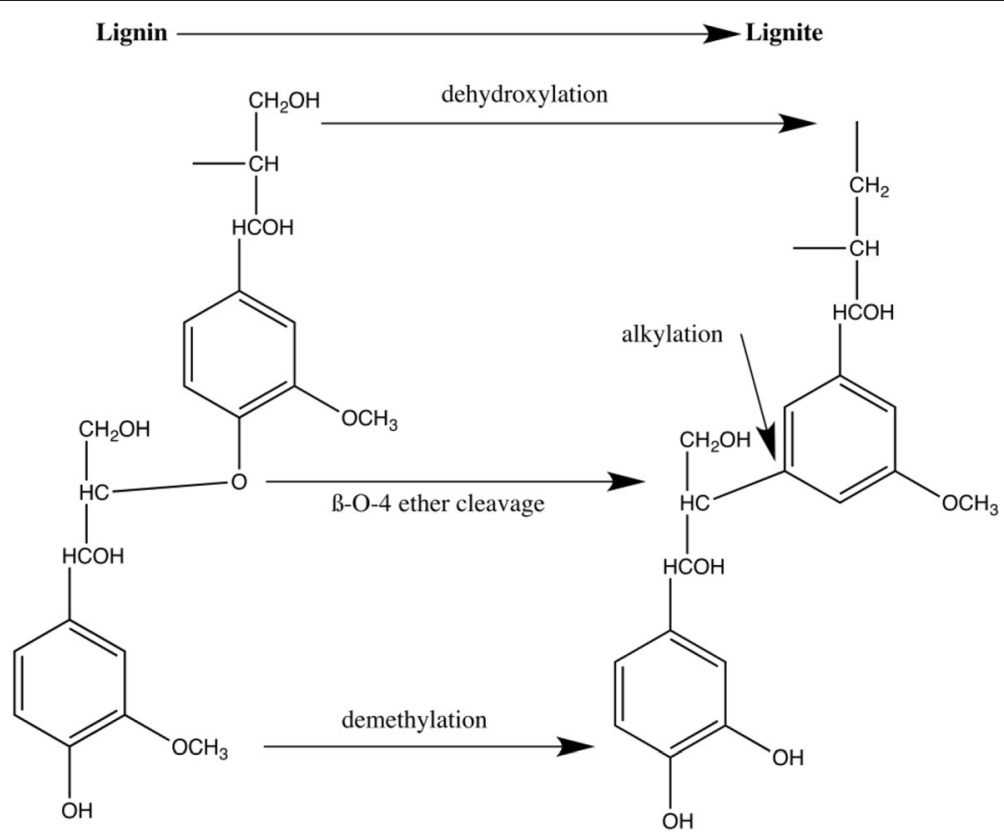

Fig. 2 Proposed coalification process from lignin to lignite coal [36] 
Under a US Department of Agriculture grant, the Northwest Advanced Renewables Alliance (NARA) of public universities, government laboratories, and private industry is attempting to stand up an economically viable supply chain from woody biomass to a variety of biorefinery value stream outputs (www.nararenewables.org). The valorization of biorefinery lignin has received much attention by NARA researchers and is viewed as a critical value-added component of the project's technical economic analysis [37]. One of the opportunities identified by the NARA interdisciplinary teams to add value to waste lignin is the development of an emission-absorbent PAC product. The PAC market opportunity attractiveness has been greatly enhanced by recent US regulations to mitigate mercury emissions from power plant flue gas [32]. The market for PAC in North America is expected to grow at a compound annual growth rate (CAGR) of $13.5 \%$ in volume and $15.9 \%$ in revenue between 2013 and 2019 with the Mercury and Air Toxic Standards (MATS) as the primary market driver, thus offering an attractive opportunity for lignin-based PAC [33]. As a result, the authors were tasked to further investigate the market opportunity for PAC from biorefinery lignin waste.

\section{Market drivers}

In December 2011, the EPA signed the MATS rule under the Clean Air Act section 111 (standards of performance for new stationary sources) and section 112 (hazardous air pollutants) requiring coal-fired power plants over $25 \mathrm{MW}$ to reduce their toxic emissions by April 2016 [38]. The MATS called for existing and new power plants to cut mercury emissions by $91 \%$ from 2010 levels with a cost to power plants estimated at approximately $\$ 9.6$ billion per year $[38,39]$. The MATS were brought to the US Court of Appeals for the D.C. Circuit in April 2014, where the ruling was upheld in a 2-1 decision [40]. On November 25, 2014, the Supreme Court of the United States (SCOTUS) agreed to hear the case by consolidating three cases (Michigan, et al. v. EPA, Utility Air Regulatory Group v. EPA et al., and National Mining Assoc. v. EPA et al.) focused on the limited question of "Whether the Environmental Protection Agency unreasonably refused to consider costs in determining whether it is appropriate to regulate hazardous air pollutants emitted by electric utilities" [41].

In March 2015, the SCOTUS over-ruled the MATS due to the EPA's lack of consideration of the costs associated with MATS implementation [42]. As a result, the EPA proposed supplemental cost of MATS data in November 2015, suggesting that the costs of the MATS "does not alter the EPA's previous determination that it is appropriate to regulate air toxics, including mercury, from power plants" [43]. A date to readdress the SCOTUS ruling on MATS has yet to be released. Regardless, the US Energy Information Administration (EIA) has reported that $77 \%$ of the nation's coal-fired power fleet has or will have met the emission regulations by installing emission controls by 2016 [44, 45].

\section{Powdered activated carbon for mercury sequestration}

The combustion of coal feedstock in power plants releases mercury emissions into the biosphere where it is transformed into methylmercury, a neurotoxin [30, 46, 47, 48]. The USA contains three main coal producing regions: Western Region (approx. 53\%), Appalachian Region (approx. 27.4\%), and Interior Region (approx. 18.6\%) [49]. Mercury emissions are a function of both the mercury content and calorific value (BTUs) of the coal, which varies by coal-producing region [50]. The Appalachian region generally has the highest mercury content (ppm) and the Western Region the lowest [50, 51].

Mitigating mercury from power plants can be achieved through various mechanisms including controls for particulate matter, sulfur dioxide, and nitrogen oxides [52]; the reinjection of partially combusted coal, known as The Thief Process [53]; and, the most effective mechanism, activated carbon injection systems (ACI) where the mercury-contaminated PAC is disposed safely in landfills or used as a concrete amendment [54-57].

\section{Lignin-based powdered activated carbon}

Lignin is approximately $60 \%$ carbon and has a structure similar to bituminous coal, thus providing an opportunity as a renewable high carbon feedstock for the manufacture of carbon fiber and activated carbon [17, 34, 58-60]. Activated carbon has been produced from high carbon content materials such as hardwoods, coconut shells, fruit stones, coals, and synthetic macromolecular systems [61]. Activated carbon is used in liquid phase and gas phase applications [61] and may be used in various forms including powdered, granulated, and extruded activated carbon [62].

Scientists have developed lignin-based PAC products through physical and chemical activation pathways [4, 34]. Lignin-based PAC has been studied for its use in liquid phase applications [63]; however, in laboratory settings, NARA researchers have successfully applied lignin-based PAC in a gas phase application to sequester mercury from power plant flue gas streams (I. Dallmeyer, personal communication, November 10, 2015). Various performancebased, market-entry issues including, but not limited to, PAC porosity and mercury capture rates are currently under investigation [I. Dallmeyer, personal communication, October 15, 2015].

\section{Objectives}

This paper provides a roadmap to identify and assess value-added markets for industrial products through an examination of lignin-based products. One value-added lignin product with potential, PAC, is used to further 
demonstrate a market analysis-based process for examining market opportunities for biorefinery lignin waste streams.

\section{Methods}

This research deployed a multi-phase market analysisbased process including a PAC vendor content analysis and survey techniques. A thorough literature review identified potential lignin-based value-added products. PAC was selected as an appropriate "low-hanging" opportunity for biorefinery waste lignin and, as such, was used in subsequent research phases. Phase I then analyzed web-based content of PAC vendors' promotional marketing literature tailored to power plant buyers/users for their PAC products. And, phase II incorporated the phase I results into an exploratory e-survey of select PAC buyers/users in the US power generation industry. Combining these methods provides an exploratory market perspective on lignin valorization.

\section{Phase I: PAC vendor content analysis}

In 2015, nine firms supplied PAC for mercury sequestration to US coal-fired power plants, eight of which were used in the vendor content analysis due to a lack of PACspecific promotional marketing material from one of the vendor websites. The population was identified through activated carbon market research reports (Table 2) [18, 32, 64-66].

\section{Content analysis}

The goal of a content analysis is "to provide knowledge and understanding of the phenomenon under study" [67] and "to examine trends and patterns in documents" [68]. Content analysis is used to isolate important service and product attributes, access attributes unpublished in peer-reviewed literature, and reduce the use of time-consuming buyer interviews [69].

Table 2 PAC vendors analyzed in the vendor content analysis $(n=8)$

\begin{tabular}{ll}
\hline PAC vendor & Print media access \\
\hline ADA Carbon Solutions & www.ada-cs.com \\
Albemarle Corporation & www.albemarle.com \\
Babcock Power Inc. & www.babcockpower.com \\
Cabot Carbon & www.cabotcorp.com \\
Calgon Carbon & www.calgoncarbon.com \\
Carbotech AC GMBH & Carbotech.de/?lang =en \\
Donau Chemie & www.donau-carbon.com/?lang=en-US \\
Jacobi Carbon & www.jacobi.net \\
CECA $^{a}$ & www.cecachemicals.com \\
\hline
\end{tabular}

${ }^{\mathrm{a}}$ Not included in vendor content analysis
This study used a summative content analysis [70] to identify and quantify specific terminology using a word frequency count (WFC) applied to the promotional marketing materials of eight US PAC suppliers. The WFC and text interpretation were categorized using a priori coding [68]. Content analysis media included all material related directly to mercury sequestration from flue gas streams from the company websites, product brochures, and product tech sheets of eight US PAC supplying companies.

PAC vendors' online promotional marketing materials may be categorized as follows (in percent of total online pages): product brochures (56\%), webpages (35\%), and product tech sheets (9\%) (Fig. 3). Product brochures establish company expertise and present products to meet customer needs, typically with minimal technical product details. Webpages, the most general form of promotional marketing material, address general information about the company and serve as the gateway to product specifications. Product tech sheets, the most technical promotional marketing material, generally provide product specifications and specific applications. Product and services attributes, derived from the content in these three web-based promotional venues, are subsequently used in phase II.

\section{Vendor attribute development}

Research suggests that industrial purchases are made on a set of value dimensions relating to product and service benefits or attributes [71]. The PAC vendor content analysis provided a systematic process to identify and code terminology into two mutually exclusive categories, product attributes and service attributes. A WFC was performed using MAXQDA software, identifying individual attributes mentioned most often, which were assumed to reflect high importance [68]. The attribute was then evaluated in the context of the document and sentenced to validate its importance to the analysis.

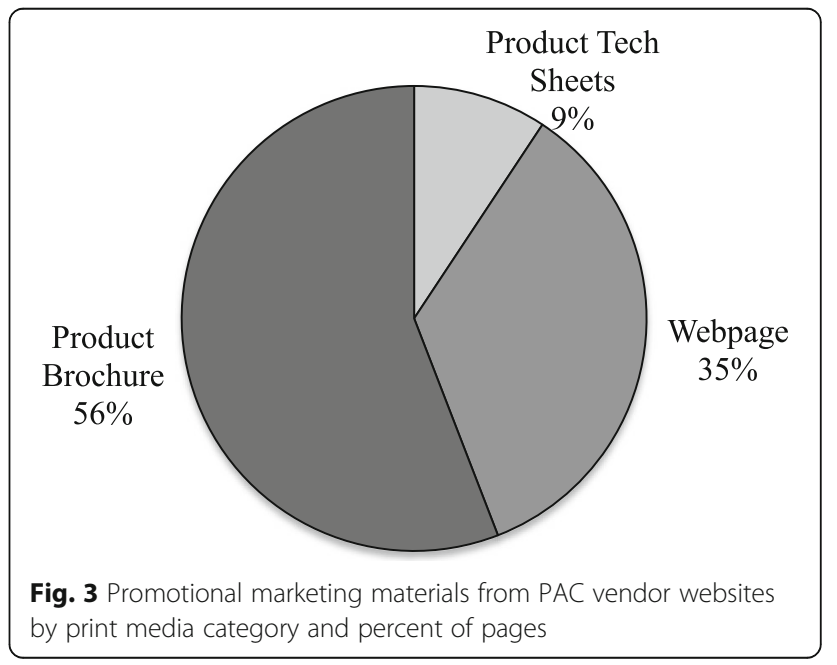


Moreover, phrases and text were interpreted to code inferred attributes into individual attributes (Table 3). The counted words and phrases were coded by individual attributes that best reflected the meaning of the word or phrase.

\section{Coders and coding}

In order to assess the reliability and validity of a content analysis, two or more coders are required [72, 73]. This study used two coders, one graduate and one undergraduate student at Penn State University, to validate the reliability of the content analysis.

\section{Phase II: PAC buyer/user survey}

Buyers/users of PAC, that is, electric generating power plants with ACI systems, assessed the importance of the phase I product and service attributes, identified barriers to market entry, and evaluated market opportunity via an e-survey.

\section{Buyer/user population development}

The Energy Information Administration (EIA) publishes an annually updated database from EIA Form-860, which includes all buyers/users of PAC from US power plants currently operating an activated carbon injection (ACI) system or proposing to operate an ACI system. In 2014, 173 electric generating power plants using 356 ACI units were identified [74]. The population for this study is all US electric generating power plants currently operating or proposed to operate an ACI system included in a 2011 EPA online database $(n=98)$ [75]. The 2011 EPA database included the most current available contact information for US electric generating power plants $(n=98)$ with ACI units delineated $(n=261)$. As shown in Fig. 4, US power plants are located throughout

Table 3 Examples of attribute assignment to PAC suppliers' web-based content

\begin{tabular}{ll}
\hline Print media content & Attribute interpretation \\
\hline "...tailored to meet your needs." & Customizable Product \\
"...customized solutions..." & Customizable Product \\
"Reduced mercury emissions" & Product Effectiveness \\
"...effective in removing many flue gas & Product Effectiveness \\
contaminants." & \\
"...plant-tested and proven..." & Proven Product \\
"...90\% mercury removal was easily attainable & Proven Product \\
with..." & Performance \\
"...supply assurance..." & Reliable Delivery \\
"...an undisturbed supply of..." & Reliable Delivery \\
"Our Advanced Performance Guarantee..." & Product Guarantee \\
"We can guarantee..." & Product Guarantee \\
\hline
\end{tabular}

the USA with concentrations along the upper Atlantic coast and the upper Midwest.

\section{E-survey}

The e-survey used SurveyMonkey (2015) and the data collection procedures were adapted from Don Dillman's Guiding Principles for Mail and Internet Surveys [76]. First, three electric generating power plants were contacted by phone and sent a pretest e-survey to discern question ambiguity and sensitive information. From the pretest, a modified and reduced five-question survey was emailed as a link via SurveyMonkey (2015) to all remaining electric generating power plants $(n=95)$ along with a cover letter explaining the purpose of the study and the confidentiality of responses. Follow-up efforts included three reminder emails at 1-week intervals.

The overall response rate was 26.6\% (17/64) after adjusting for unreachable power plants $(n=34)$ due to erroneous contact information in the EPA (2011) online database. The adjusted population for this exploratory study included 64 electric generating power plants with valid contact information from the EPA's most current available database [75]. Of the 17 participants, 4 are located in the upper Atlantic coast region, 1 in Florida, 7 in the upper mid-west, and 5 in the western USA.

\section{Results}

Phase I: PAC vendor content analysis

PAC suppliers utilize promotional marketing materials; product brochures, company websites, and product technical sheets to market products toward customers for the application of mercury sequestration from power plant flue gas. The print media consisted of 163 pages with 486 word frequency counts (WFCs); Product attributes received 408 WFCs, and service attributes received 78 WFCs.

\section{Product and service attributes}

Following compilation of the product and service attribute word frequency count (WFC), individual attributes were tallied based on frequency. Overall, vendors of PAC convey a general message to buyers/users that their products will meet customer needs through product attributes. Based on WFCs, the top three attributes conveyed by vendors about their products were Concrete Friendly (WFC $=76$ ), Product Effectiveness (WFC $=60$ ), and Product Reliability $($ WFC $=44)$ (Table 4$)$. The service attributes most frequently mentioned were Reliable Delivery (WFC $=39)$ and ACI Installations (WFC = 18) (Table 4). Analysis of the product and service attributes from the promotional marketing material provides insight into vendors' product positioning and communication strategies. 


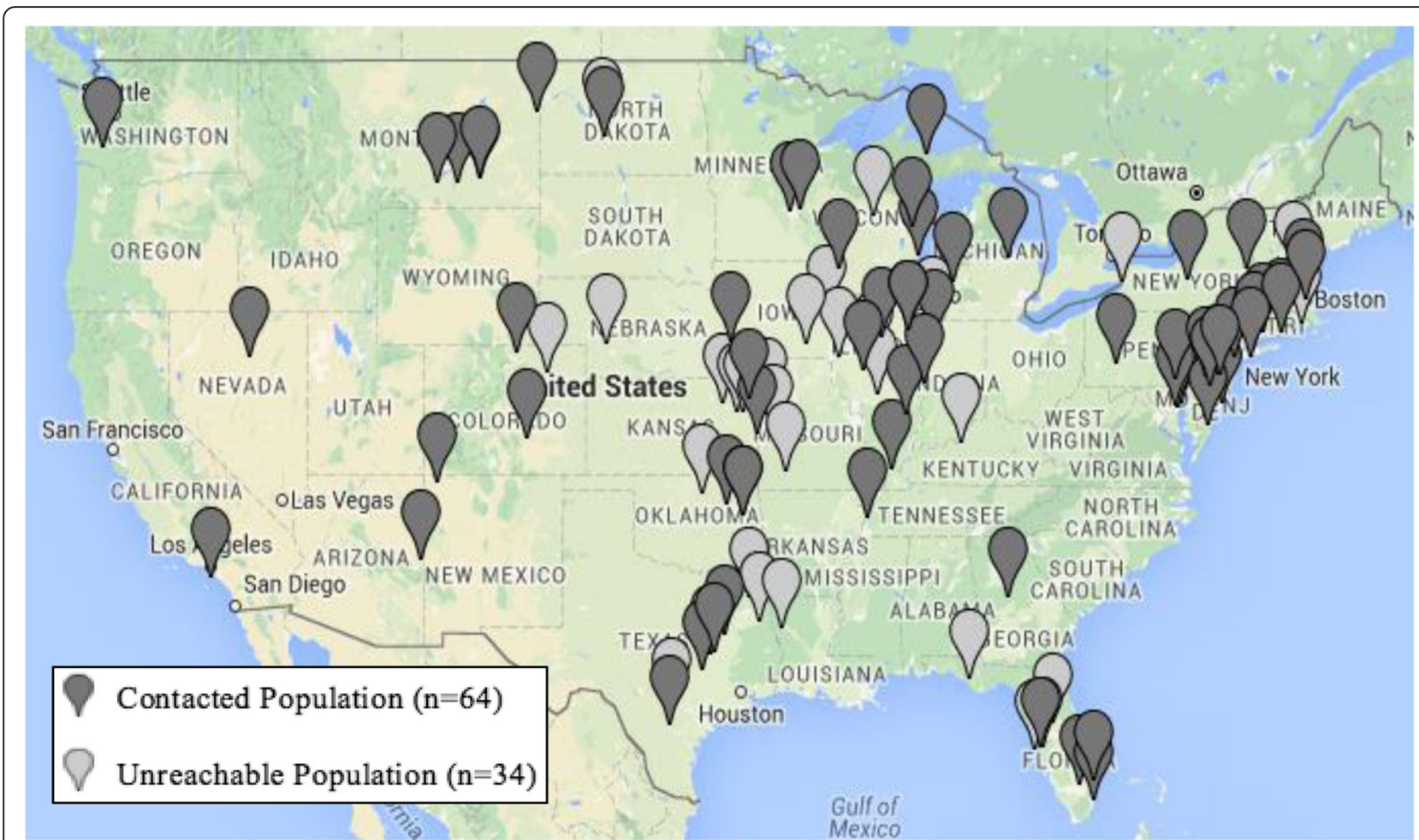

Fig. 4 Map of all US power plants included in the EPA online database (2011) $(n=98)$ delineating the contacted power plants (dark nodes; $n=64)$ and the unreachable power plants (light nodes; $n=34)(E I A, 2011)$

Table 4 Word frequency count of 13 product and service attributes identified in the content analysis of PAC vendors' promotional marketing materials

\begin{tabular}{ll}
\hline 9 product attributes & Word frequency count (WFC) \\
Concrete Friendly & 76 \\
Product Effectiveness & 60 \\
Product Reliability & 44 \\
Density & 41 \\
Product Efficiency & 41 \\
Ignition Temperature & 39 \\
Injection Rate & 38 \\
Proven Product Performance & 35 \\
Customizable Product & 32 \\
Total (product attributes) & 408 \\
4 service attributes & Word frequency count (WFC) \\
Reliable Delivery & 39 \\
ACl Installations & 18 \\
On-Site Support & 12 \\
Product Guarantee & 10 \\
Total (service attributes) & 78 \\
Total (13 product and service attributes) & 486 \\
\hline
\end{tabular}

The distribution of WFCs shows vendors' strategy to promote their PAC products as competent in product attributes with less emphasis on service attributes. Product attributes captured $84 \%$ of the total WFCs, while service attributes captured $16 \%$. To gain perspective on importance from buyers/users of PAC, this population was surveyed using the above attributes.

\section{Phase II: PAC buyer/user survey}

From the content analysis, product and service attributes promoted by PAC vendors were included in a PAC buyer/user questionnaire. In addition, questions were added to address barriers to market entry for a new PAC product and opportunities for PAC product substitution.

\section{Powdered activated carbon product and service attributes}

In addition to the 13 product and service attributes derived from the content analysis of vendors' promotional materials, Just-in-Time Delivery, Vendor Managed Inventory, and Delivered Price were added as research controls to ascertain the veracity of the vendor content analysis. Additionally, List of Usage References was added as a result of a personal communication suggestion from a PAC industry consultant. These four attributes are shown in Fig. 5 without WFCs. As a result, PAC buyers/users at US 


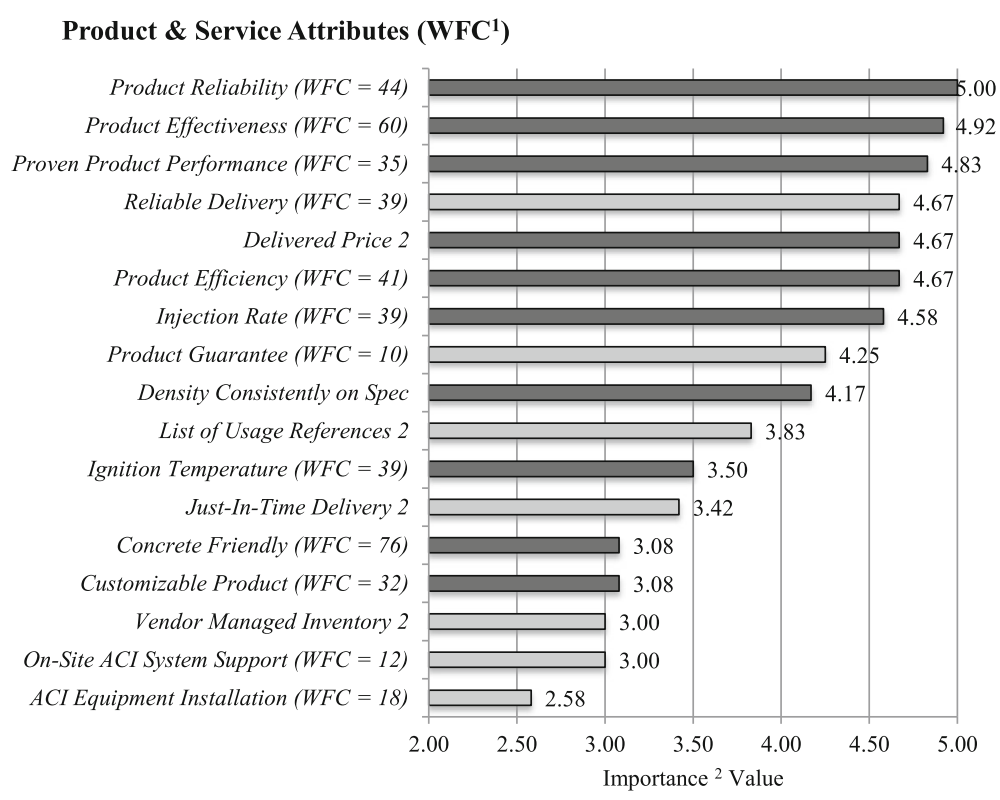

Fig. 5 Product and service attribute ratings by PAC buyers/users from US electric generating power plants $(n=17)$

electrical generation power plants were asked about PAC 17 product and service attributes as follows:

Question: [on a 5-point scale from $1=$ unimportant to $3=$ neither important nor unimportant to $5=$ extremely important] How IMPORTANT to your plant are the following PRODUCT and SERVICE attributes in the purchase of your powdered activated carbon product?

Product Reliability was rated as the most important attribute by buyers/users of PAC (mean $=5)$, followed by Product Effectiveness, Proven Performance, Reliable Delivery, Delivered Price, and Product Efficiency (Fig. 5). The least important attribute was ACI Equipment Installation (mean $=2.58$ ). The highest rated service attribute was Reliable Delivery (mean $=4.67$ ), followed by Product Guarantee (mean $=4.25$ ), and List of Usage References $($ mean $=3.83)$. The 10 product attributes (overall mean $=4.25)$ were, as a whole, rated higher than the 7 service attributes $($ mean $=3.53)$. Interestingly, PAC buyers/users rated Product Reliability, Effectiveness and Performance higher than Delivered Price, suggesting opportunities to differentiate products on performance attributes.

An alignment in marketing strategy between what customers find most important and how vendors market their products was found through a comparison of the vendor content analysis and the e-survey attribute importance. Buyers/users of PAC rated Product Reliability $($ mean $=5.00)$, Product Effectiveness $($ mean $=4.92)$, and Proven Product Performance (mean $=4.83$ ) as the three most important attributes when considering a product for purchasing, while vendors of PAC, market Product Effectiveness (WFC $=60$ ) and Product Reliability
$(\mathrm{WFC}=44)$, as the second and third most often compared to other attributes (Fig. 5). Buyers/users also rated Reliable Delivery (mean $=4.67$ ) the most important service attribute; consistent with vendors' promotional material emphasis with this service attribute mentioned the most, by far (WFC = 39). Surprisingly, Concrete Friendly was rated as relatively low in importance by PAC buyers/users (mean $=3.08$ ), but vendors' promotional materials mention this attribute the most frequently in their on-line promotional materials $(\mathrm{WFC}=76$ ).

\section{Barriers to entry}

Another issue addressed in the e-survey to PAC buyers at US electric generating power plants concerned potential entry barriers for a new, lignin-based PAC product. Specifically, respondents were asked to list (un-aided) in rank-order the top three barriers to their purchase of a new lignin-based PAC. The buyer/user entry barrier responses were given a value weighting of 5 points for the largest barrier, 3 points for the second largest barrier, and 1 point for the third largest barrier (Fig. 6). The barriers to entry were addressed as follows:

Question: [on a 5-point scale from $1=$ extremely unlikely to $3=$ neither unlikely nor likely to $5=$ extremely likely] Please indicate the top 3 barriers to a new ligninbased PAC product for your power plant.

Title V Permits (weighted score $=18$ ), such as a permit required for any physical plant change or change in the methods of plant operation, and Operational Impacts (weighted score $=16$ ), that is, any impact on plant operations such as down-time or equipment change-over, represent the top two barriers to market entry for a 


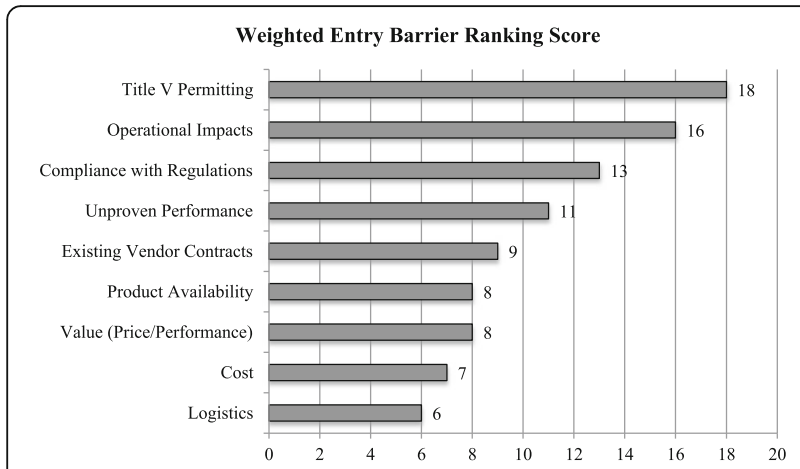

Fig. 6 Barriers to entry for a new lignin-based PAC product $(n=13)$

lignin-based PAC, followed by Compliance with Regulations (weighted score $=13$ ), specifically, compliance with mercury emission regulations, and Unproven Performance (weighted score $=11$ ), that is, a product not yet tested on a full-scale power plant (Fig. 6). Additional entry barriers to a new lignin-based PAC products mentioned by PAC buyer/users include Existing Vendor Contracts (weighted score = 9), Product Availability (score $=8)$, Cost (weighted score $=7$ ), and Logistics (transportation and distribution concerns) (weighted score $=6)$.

\section{Opportunities for substitution}

Finally, the e-survey asked PAC buyers/users to indicate the likelihood that their power plant would test trial a new lignin-based PAC and their likeliness of purchasing a new lignin-based PAC from an existing vendor or a new vendor. The 13 respondents who answered the previous "...barriers to a new lignin-based PAC product for your power plant" (entry barriers) question were asked the following two questions:

Question: [on a 5-point scale from $1=$ extremely unlikely to $3=$ neither unlikely nor likely to $5=$ extremely likely] Please indicate how LIKELY your plant is to consider a trial test for proof-of-concept of a lignin-based PAC, assuming similar price and performance as your current product?

Question: [on a 5-point scale from $1=$ extremely unlikely to $3=$ neither unlikely nor likely to $5=$ extremely likely] If the trial test proved lignin-based PAC to be a comparable product, how LIKELY is your plant to purchase lignin-based PAC from an Existing Vendor, or a New Vendor?

Buyers/users of PAC rated the likelihood of trial testing a new lignin-based PAC for proof-of-concept as 2.47 (5-point scale) with a standard deviation of $1.19(n=13)$ (Fig. 7). Respondents then indicated a somewhat stronger likelihood of purchasing a lignin-based PAC from an existing vendor at 3.00 with a standard deviation of 1.00

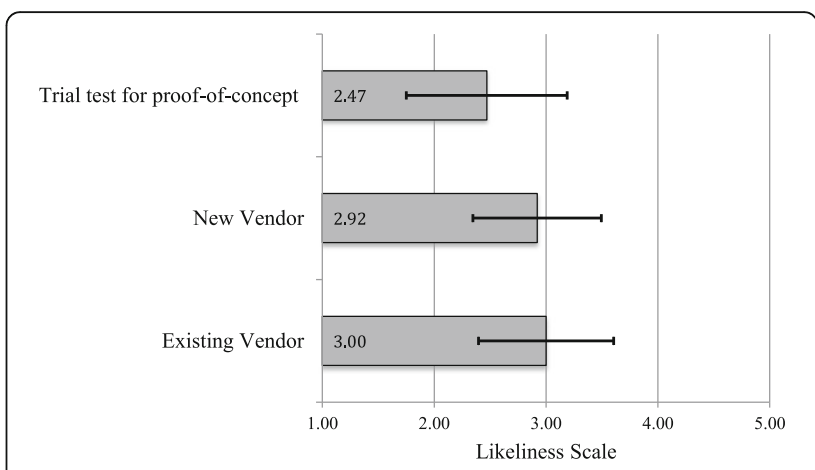

Fig. 7 PAC buyers/users' likeliness to consider purchasing ligninbased PAC from a new or existing vendor $(n=13)$

$(n=13)$ and $2.92(n=13)$ from a new vendor with a standard deviation of 0.95 .

\section{Discussion and conclusions}

PAC, a potential value-added opportunity for lignin, has an established and growing market in the USA. Current research suggests that PAC is a technically viable opportunity for lignin waste streams from pulp mills and biorefineries partially due to lignin's similarities to lignite coal, the primary feedstock for PAC in this application. This study presents a multi-phase exploratory process for evaluating opportunities for lignin valorization as follows:

- (Phase I) PAC vendor content analysis to derive product and service attributes on which PAC products are promoted and sold

- (Phase II) PAC buyer/user exploratory e-surveys to address the relative importance of the phase I product and service attributes and to examine entry barriers for new PAC products and the market opportunity for a lignin-based PAC.

The PAC vendor content analysis suggests that vendors tailor the content of their promotional marketing materials to convey salient company and product information to their customers. PAC vendors promoted the product attributes of PAC (WFC $=408)$ more frequently than service attributes (WFC $=78$ ) as evidenced by higher overall word frequency counts (WFCs). Concrete Friendly (WFC = 76), Product Effectiveness $(\mathrm{WFC}=60)$, and Product Reliability $(\mathrm{WFC}=44$ ) received the highest overall WFCs in vendor PAC promotions. Reliable Delivery $(\mathrm{WFC}=39)$ and ACI Installation (WFC $=18$ ) ranked as the top two service attributes in which PAC vendors promoted their products. The WFCs of the product and service attributes from the PAC vendor content analysis reveal that PAC vendor marketing of a cost-effective, well performing 
product that will accomplish the goals of the power plant is important to the strategy of PAC marketing.

Results from surveying the buyer/user population of US electric generating power plants revealed the 10 product attributes $($ mean $=4.25)$ in which PAC buyers/users purchase their PAC to sequester mercury from flue gas streams rated higher than the 7 service attributes (mean $=3.53$ ) in which PAC buyers/users purchase their PAC to sequester mercury from flue gas streams. Product Reliability $($ mean $=5.00)$, Product Effectiveness (mean $=4.92$ ), and Proven Product Performance $($ mean $=4.83)$ ranked the three most important attributes. Reliable Delivery $($ mean $=4.67)$, Product Guarantee $($ mean $=4.25)$, and List of Usage References (mean $=3.83$ ) ranked as the three most important service attributes. The product and service attributes ranked by buyers/users of PAC for mercury sequestration indicated products for purchase consideration must be reliable in mitigating mercury from flue gas streams and effective in mercury sequestration and must have a record of proven performance in existing full-scale power plants.

Respondents indicated the top three barriers to entry as Title V Permit (weighted score $=18$ ), Operational Impacts (weighted score $=16$ ), and Compliance with Regulation (weighted score $=13$ ). Buyers/users of PAC, overall, rated their likeliness to trial test a new ligninbased PAC for proof of concept relatively low at 2.47 $(n=13)$. However, they were somewhat more likely to purchase a proven (trial tested) lignin-based PAC from an existing vendor (mean $=3.00$ ) or from a new vendor $($ mean $=2.92)$, suggesting that they would be slightly more receptive to a proven product than spending energy being part of the test trial process. This hesitation to trial test a new lignin-based PAC for mercury sequestration from power plant flue gas may be due, in part, to the PAC Title V Permitting process, concerns over possible operational impacts, such as power plant downtime, and/or apprehension for meeting emission regulations due to product switching.

This exploratory study has implications to industry, policy makers, and academia and provides insights to the PAC producing industry, biorefineries, and the pulp industry regarding the market potential for introducing a lignin-based PAC as a value-added option for mercury sequestration from power plant flue gas streams. Policy makers may better understand the impact and reaction of new rules on electric generating power plants and peripheral industries. Lastly, this work illustrates a framework for exploring value-added business-to-business productmarket opportunities and, specifically, opportunities for lignin valorization with a particular application to ligninbased PAC for mercury sequestration from electric generating power plant flue gas.

\section{Limitations}

Results of this study may be considered as exploratory due to the relatively small population size of 64 electric generating power plants with usable contact information and a limited response of 17 surveys. Whereas the process used in this study may be applied to multiple emerging ligninbased products across a wide array of industrial applications, this paper addresses a single lignin valorization market opportunity, lignin-based PAC. The findings, however, may lay the groundwork for future work exploring market opportunities in other business-tobusiness markets.

\section{Acknowledgements \\ This work was funded by the US Department of Agriculture's National Institute of Food and Agriculture (NIFA) Agriculture and Food Research Initiative Competitive Grant No. 2011-68005-30416, Northwest Advanced Renewables Alliance (NARA) project.}

\section{Authors' contributions}

SC designed the study, developed the population, designed the survey, and analyzed and deduced the results. PS aided in designing the study as well as the survey. Both authors read and approved the final manuscript.

\section{Authors' information}

SC was a Masters of Science student of BioRenewable Systems in the Agricultural and Biological Engineering department at The Pennsylvania State University. He now works as a Research \& Development Engineer at Saint Gobain CertainTeed. PS is a Professor, Bioproducts Marketing in the Department of Agricultural and Biological Engineering at the Pennsylvania State University.

\section{Competing interests}

The authors declare that they have no competing interests.

\section{Publisher's Note}

Springer Nature remains neutral with regard to jurisdictional claims in published maps and institutional affiliations.

Received: 14 December 2016 Accepted: 3 August 2017

Published online: 28 August 2017

\section{References}

1. ElA (2015b) How much ethanol is in gasoline, and how does it affect fuel economy. http://www.eia.gov/tools/faqs/faq.cfm?id=27\&t=10. Accessed 4 Feb 2016

2. Naik SN, Goud W, Rout PK, Dalai AK (2010) Production of first and second generation biofuels: a comprehensive review. Renew Sust Energ Rev 14(2): 578-597. https://doi.org/10.1016/j.rser.2009.10.003

3. Langholtz M, Downing M, Graham R, Baker F, Compere A, Griffith W, Keller M (2014) Lignin-derived carbon fiber as a co-product of refining cellulosic biomass. SAE International Journal of Materials \& Manufacturing 7(1):115-121

4. Ragan S, Megonnell N (2011) Activated carbon from renewable resources_lignin. Cellul Chem Technol 45(7):527

5. Sims REH, Mabee W, Saddler JN, Taylor M (2010) An overview of second generation biofuel technologies. Bioresour Technol, 101(6), 1570-1580. https://doi.org/10.1016/j.biortech.2009.11.046

6. Boerjan W, Ralph J, Baucher M (2003) Lignin biosynthesis. Annu Rev Plant Biol 54:519-546. https://doi.org/10.1146/annurev.arplant.54.031902.134938

7. Sannigrahi P, Pu Y, Ragauskas A (2010) Cellulosic biorefineries-unleashing lignin opportunities. Curr Opin Environ Sustain 2(5-6):383-393. https://doi. org/10.1016/j.cosust.2010.09.004

8. Brauns FE (1948) Lignin-a botanical raw material. Econ Bot 2(4):419-435

9. McCarthy JL, Islam A (1999) Lignin chemistry, technology, and utilization: a brief history. In lignin: historical, biological, and materials perspectives. Am Chem Soc 742:1-2. https://doi.org/10.1021/bk-2000-0742.ch001 
10. Li SH, Liu S, Colmenares JC, Xu YJ (2016) A sustainable approach for lignin valorization by heterogeneous photocatalysis. Green Chem 3(18):596-607

11. Linger JG, Vardon DR, Guarnieri MT, Karp EM, Hunsinger GB, Franden MA, Pienkos PT (2014) Lignin valorization through integrated biological funneling and chemical catalysis. Proc Natl Acad Sci 111(33):12013-12018

12. Strassberger $Z$, Tanase $S$, Rothenberg G (2014) The pros and cons of lignin valorisation in an integrated biorefinery. RSC Adv 4(48):25310-25318

13. Vardon DR, Franden MA, Johnson CW, Karp EM, Guarnieri MT, Linger JG, Beckham GT (2015) Adipic acid production from lignin. Energy Environ Sci 8(2):617-628

14. Vishtal AG, Kraslawski $A$ (2011) Challenges in industrial applications of technical lignins. Bioresources 6(3):3547-3568

15. McCarthy JL, Islam A (2000) Lignin chemistry, technology, and utilization: a brief history, In ACS symposium series, vol 742. American Chemical Society; 1999, Washington, DC, pp 2-99

16. Zakzeski J, Bruijnincx PCA, Jongerius AL, Weckhuysen BM (2010) The catalytic valorization of lignin for the production of renewable chemicals. Chem Rev 110(6):3552-3599

17. Radotić K, Mićić M, Jeremić M (2005) New insights into the structural organization of the plant polymer lignin. Ann N Y Acad Sci 1048(1):215-229. doi:https://doi.org/10.1196/annals.1342.020

18. Freedonia (2013) Activated carbon to 2017-demand and sales forecasts, market share, market size, market leaders - table of contents. http://www. freedoniagroup.com/Activated-Carbon.html. Accessed 12 Feb 2014

19. Hayashi J, Kazehaya A, Muroyama K, Watkinson AP (2000) Preparation of activated carbon from lignin by chemical activation. Carbon, 38(13), $1873-$ 1878. https://doi.org/10.1016/S0008-6223(00)00027-0

20. Mohammad-Khah A, Ansari R (2009) Activated charcoal: preparation, characterization and applications: a review article. Int J ChemTech Res 1(4): 859-864

21. Gargulak JD, Lebo SE (1999) Commercial use of lignin-based materials. In lignin: historical, biological, and materials perspectives. Am Chem Soc 742: 15-304. https://doi.org/10.1021/bk-2000-0742.ch015

22. Lora JH, Glasser WG (2002) Recent industrial applications of lignin: a sustainable alternative to nonrenewable materials. J Polym Environ 10(1-2):39-48

23. Mansouri NE El, Salvadó J (2006) Structural characterization of technical lignins for the production of adhesives: application to lignosulfonate, kraft, soda-anthraquinone, organosolv and ethanol process lignins. Ind Crop Prod, 24(1), 8-16. https://doi.org/10.1016/j.indcrop.2005.10.002

24. Smolarski N (2012) High-value opportunities for lignin: unlocking its potential. http://www.frost.com/sublib/display-market-insight-top.do?id= 269017995. Accessed 10 Sep 2015

25. Higson A, Smith C (2014) NNFCC: renewable chemicals factsheet: lignin. http://www.nnfcc.co.uk/publications/nnfcc-renewable-chemicals-factsheetlignin/at_download/file. Accessed 16 Jun 2015

26. Borregaard (2015) The home of sustainable vanillin. www.smartvanillin.com. Accessed 28 Jan 2016

27. Tillman D (1985) Forest products: advanced technologies and economic analysis. Academic Press, Orlando

28. Frost \& Sullivan (2014) Full speed ahead for the lignin market with highvalue opportunities as early as 2017. http://www.frost.com/prod/servlet/ press-release-print.pag?docid=290584323. Accessed 12 Jan 2015

29. Kleinert M, Barth T (2008) Phenols from lignin. Chem Eng Technol 31(5): 736-745. https://doi.org/10.1002/ceat.200800073

30. Cherubini F, Strømman AH (2011) Chemicals from lignocellulosic biomass: opportunities, perspectives, and potential of biorefinery systems. Biofuels Bioprod Biorefin 5(5):548-561. https://doi.org/10.1002/bbb.297

31. Rinaldi R, Jastrzebski R, Clough MT, Ralph J, Kennema M, Bruijnincx PCA, Weckhuysen BM (2016) Angew Chem Int Ed 55:8164

32. Anonymous (2013) Transparency market research. Activated carbon market (powdered, granular) for liquid phase and gas phase applications in water treatment, food \& beverage processing, pharmaceutical \& medical, automotive and air purification-global industry analysis, size, share, growth, trends. http://www.transparencymarketresearch.com/activatedcarbon-market.html. Accessed 7 Aug 2014

33. Anonymous (2015) Transparency market research. Activated carbon market for mercury sequestration: global industry analysis, size, share, growth, trends and forecast 2013-2019

34. Suhas Carrott PJM, Carrott, MML R (2007) Lignin-from natural adsorbent to activated carbon: a review. Bioresour Technol, 98(12), 2301-2312. https://doi. org/10.1016/j.biortech.2006.08.008
35. Miller BG (2011) The chemical and physical characteristics of coal BT - Clean Coal engineering technology (pp. 53-68). Boston: Butterworth-Heinemann. https://doi.org/10.1016/B978-1-85617-710-8.00002-9

36. Hatcher PG, Clifford DJ (1997) The organic geochemistry of coal: from plant materials to coal. Org Geochem 27(5-6):251-274. https://doi.org/10.1016/ S0146-6380(97)00051-X

37. Fish D, Dallmeyer I, Fox C, Eatherton R, Cline S, Casayuran C, Garcia-Perez M, Suliman W, Haynes S (2016) Conversion of lignin to high value, large market products. Northwest advanced Renewables alliance final report. https:// nararenewables.org/documents/2017/05/conversion-of-lignin-to-high-valuelarge-market-products.pdf. Accessed 13 Jul 2017

38. EPA (2012) Fact sheet: mercury and air toxic standards for power plants. Retrieved https://www.epa.gov/sites/production/files/2015-11/documents/ 20111221 matssummaryfs.pdf. Accessed 13 Aug 2014.

39. Ray R (2015) What you need to know about the clean power plan. http:// www.power-eng.com/blogs/power-points/2015/09/what_you_need_tokno. html. Accessed 15 Feb 2016

40. Larson A (2015) Supreme court strikes down EPA's MATS rule. http://www. powermag.com/supreme-court-strikes-down-epas-mats-rule/. Accessed 15 Feb 2016

41. Reitenbach G (2014) Supreme court agrees to consider MATS case. http:// www.powermag.com/supreme-court-agrees-to-consider-mats-case/. Accessed 15 Feb 2016

42. Neuhauser A (2015) EPA mercury rule for power plants goes before supreme court. U.S. news \& world report. http://www.usnews.com/news/ articles/2015/03/24/epa-mercury-rule-for-power-plants-goes-beforesupreme-court. Accessed 13 May 2015

43. EPA (2016) Fact sheet: consideration of cost in the appropriate and necessary finding for the mercury and air toxics standards for power plants. https://www.epa.gov/sites/production/files/2016-05/documents/20160414_ mats_ff_fr_fs.pdf. Accessed 15 Oct 2015

44. Frazier R (2016) Coal-fired power plants clean up their act. Inside Energy. http://insideenergy.org/2016/01/06/coal-fired-power-plants-clean-up-theiract/\#. Accessed 10 Jan 2016

45. Gray P, Rubin J, Yost N (2015) MATS attack: supreme court reversal of EPA's air toxics rule signals difficulties ahead. http://www.jdsupra.com/legalnews/ mats-attack-supreme-court-reversal-of-78132/. Accessed 5 Jan 2016

46. Chang LW (1977) Neurotoxic effects of mercury-a review. Environ Res, 14(3), 329-373. https://doi.org/10.1016/0013-9351(77)90044-5

47. Bowen B, Irwin M (2007) Basic mercury data \& coal fired power plants. In Indiana center for coal technology research. https://www.purdue.edu/ discoverypark/energy/assets/pdfs/cctr/outreach/Basics2-Mercury-Mar07.pdf. Accessed 10 May 2015

48. Hu H, Lin H, Zheng W, Tomanicek SJ, Johs A, Feng X, Gu B (2013) Oxidation and methylation of dissolved elemental mercury by anaerobic bacteria. Nat Geosci, 6(9), 751-754. Retrieved from https://doi.org/10.1038/ngeo1894

49. ElA (2016) Coal data browser. http://www.eia.gov/beta/coal/data/browser/ \#/topic/33?agg=0,2,1\&rank=g\&geo=g0000000000003vu\&mntp=g\&linechart= COAL.PRODUCTION.TOT-US-TOT.A\&columnchart=COAL.PRODUCTION.TOTUS-TOT.A\&map=COAL.PRODUCTION.TOT-WBO-TOT.A\&freq=A\&start= 2001\&end=2013\&ctype $=$ map\&ltype $=$. Accessed 8 Feb 2016

50. Toole-O'Neil B, Tewalt SJ, Finkelman RB, Akers DJ (1999) Mercury concentration in coal-unraveling the puzzle. Fuel, 78(1), 47-54. https://doi. org/10.1016/S0016-2361(98)00112-4

51. Tewalt SJ, Bragg LJ, Finkelman RB (2001) Mercury in US coal; abundance, distribution, and modes of occurrence (no. 095-01)

52. Strivastava R (2005) Control of mercury emissions from coal-fired electric utility boilers: a update. National Risk Management Research Laboratory, Office of Research and Development, US Environmental Protection Agency. http://www3.epa.gov/airtoxics/utility/ord_whtpaper_hgcontroltech_oar2002-0056-6141.pdf. Accessed 5 Dec $201 \overline{5}$

53. Granite EJ, Freeman MC, Hargis RA, O'dowd WJ, Pennline HW (2007) The thief process for mercury removal from flue gas. J Environ Manag 84(4):628-634

54. Gray $L$ (2013) Review of control technologies for mercury emissions from coal-fired power plants. http://www.ewp.rpi.edu/hartford/ grayl3/AWPPCE/ Air/Project/A_Review_of_Control_Technologies\%20_for_Mercury_ Emissions from Coal-Fired Poweplants.pdf. Accessed 5 Oct 2015

55. Sjostrom S, Durham M, Bustard CJ, Martin C (2010) Activated carbon injection for mercury control: overview. Fuel, 89(6), 1320-1322. https://doi. org/10.1016/j.fuel.2009.11.016 
56. Sjostrom SM (2014) Activated carbon injection, in mercury control: for coalderived gas streams. In: Granite E, Pennline H, Senior C (eds) Mercury control. Wiley-VCH Verlag GmbH \& Co. KGaA, Weinheim, pp 293-310. https://doi.org/10.1002/9783527658787.ch18

57. Zykov AM, Anichkov LG, Korshevets Lk, Strel'tsova ED, Leonova Y (2014) Mercury emissions capture efficiency with activated carbon injection at a Russian coal-fired thermal power plant. https://cfpub.epa.gov/si/si_public_ record_report.cfm?dirEntryld=334370. Accessed 13 Mar 2015

58. Kadla JF, Kubo S, Venditti RA, Gilbert RD, Compere AL, Griffith W (2002) Lignin-based carbon fibers for composite fiber applications. Carbon 40(15): 2913-2920

59. Norberg I (2012) Carbon fibres from kraft lignin. KTH Royal Institue of technology. http://www.diva-portal.org/smash/get/diva2:513032/ FULLTEXT01.pdf. Accessed 10 March 2015

60. Ragauskas AJ, Beckham GT, Biddy MJ, Chandra R, Chen F, Davis MF, Wyman CE (2014) Lignin valorization: improving lignin processing in the biorefinery. Science (New York, NY) 344(6185):1246843. https://doi.org/10.1126/science. 1246843

61. Marsh H, Reinoso FR (2006) Activated carbon. Elsevier, Amsterdam

62. Cabot (2014) Activated carbon. http://www.cabotcorp.com/solutions/ products-plus/activated-carbon. Accessed 29 Oct 2014

63. Fu K, Yue Q, Gao B, Sun Y, Zhu L (2013) Preparation, characterization and application of lignin-based activated carbon from black liquor lignin by steam activation. Chem Eng J, 228(0), 1074-1082. https://doi.org/10.1016/j. cej.2013.05.028

64. Kahn S (2014) Activated carbon manufacturing in the US. http://dients1. ibisworld.com.ezaccess.libraries.psu.edu/reports/us/industry/default. aspx?entid=4484. Accessed 15 July 2014

65. Marketsandmarkets.com (2012) Activated carbon/charcoal/coal market by product (powdered, granular) \& application (water treatment, air purification, automotive, food \& beverage) — global trends \& forecasts to 2016-table of contents. http://www.marketsandmarkets.com/MarketReports/activated-carbon-362.html. Accessed 10 Jun 2015

66. PR Newswire (2013) Roskill: activated carbon could see world consumption double in four years. http://www.prnewswire.com/news-releases/roskillactivated-carbon-could-see-world-consumption-double-in-four-years198976641.html. Accessed 19 Oct 2013

67. Downe-Wamboldt B (1992) Content analysis: method, applications, and issues. Health Care for Women International 13(3):313-321. https://doi.org/ 10.1080/07399339209516006

68. Stemler S (2001) An overview of content analysis. Practical Assessment, Research \& Evaluation 7(17):137-146

69. Krippendorff K (1980) Content analysis: an introduction to its methodology. Sage, Beverly Hills

70. Hsieh HF, Shannon SE (2005) Three approaches to qualitative content analysis. Qual Health Res 15(9):1277-1288

71. Ulaga W, Eggert A (2005) Relationship value in business markets: the construct and its dimensions. Journal of Business-to-Business Marketing 12(1):73-99. https://doi.org/10.1300/J033v12n01_04

72. Kolbe RH, Burnett MS (1991) Content-analysis research: an examination of applications with directives for improving research reliability and objectivity. J Consum Res 18(2):243-250 Retrieved from http://www.jstor.org/stable/ 2489559

73. Potter WJ, Levine-Donnerstein D (1999) Rethinking validity and reliability in content analysis. J Appl Commun Res 27(3):258-284

74. EIA (2015a) Form EIA-860 detailed data. http://www.eia.gov/electricity/data/ eia860/. Accessed 3 Sep 2015

75. EPA (2011) Air toxics standards for utilities: MATS ICR data-facility contact information database. http://www.epa.gov/airtoxics/utility/utilitypg.html. Accessed 24 Sep 2014

76. Dillman D (2012) Don Dillman's guiding principles for mail and internet surveys. http://www.une.edu/sites/default/files/Microsoft-Word-GuidingPrinciples-for-Mail-and-Internet-Surveys_8-3.pdf. Accessed 29 Aug 2014

77. Downing M (2014) DOE Lignin to Carbon Fiber Workshop. http://www1. eere.energy.gov/bioenergy/pdfs/carbon_fiber_workshop_downing.pdf

78. Chen H Z (2005) Biotechnology of lignocellulose. Springer

\section{Submit your manuscript to a SpringerOpen ${ }^{\circ}$ journal and benefit from:}

- Convenient online submission

- Rigorous peer review

- Open access: articles freely available online

- High visibility within the field

- Retaining the copyright to your article

Submit your next manuscript at $\gg$ springeropen.com 